\title{
Supplementary Information for Gold Nanoparticle-Assisted Black Silicon Substrates for Mass Spectrometry Imaging Applications
}

Stefania Alexandra Iakab ${ }^{\dagger}$, Pere Ràfols ${ }^{\dagger *}$, Marta Tajes $^{\bar{\top}}$, Xavier Correig-Blanchar ${ }^{\dagger \star \S}$, Maria García-Altares $_{\dagger+}^{\dagger+}$

†Department of Electronic Engineering, Rovira i Virgili University, Tarragona, 43007, Spain † Spanish Biomedical Research Centre in Diabetes and Associated Metabolic Disorders (CIBERDEM), Madrid, 28029, Spain

${ }^{\bar{T}}$ Group of Biomedical Research in Heart Diseases, IMIM (Hospital del Mar Medical Research Institute), Barcelona, 08003, Spain.

§Institut d'Investigacio Sanitària Pere Virgili, 43204, Tarragona, Spain

*Email: pere.rafols@urv.cat

Keywords: black silicon, gold, nanostructured surface, functionalization, mass spectrometry imaging, imprinting 

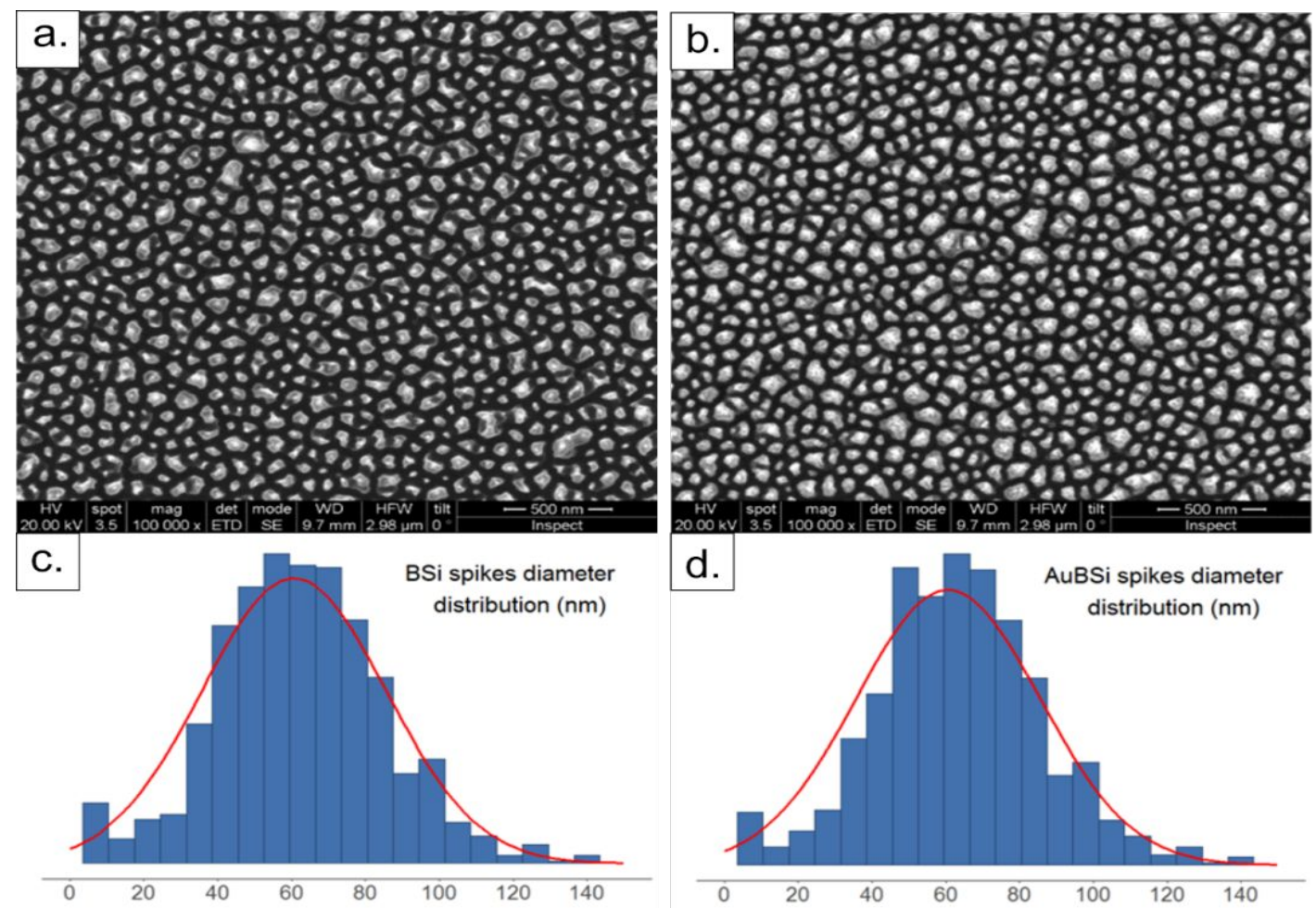

Figure S1. SEM images of the top view of BSi (a) and AuBSi (b) with their respective mean diameter size distribution around $60 \mathrm{~nm}$ (c and d)
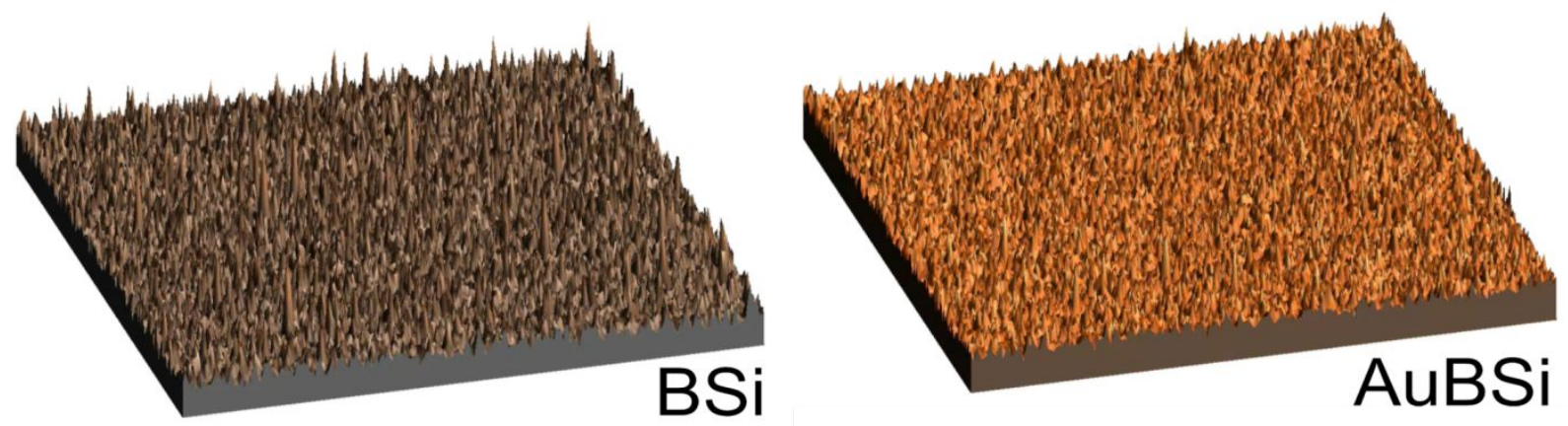

Figure S2. 3D profile roughness measurements of BSi and AuBSi. The average Roughness of BSi and AuBSi surfaces is $15.9378 \mathrm{~nm}$ and $16.0352 \mathrm{~nm}$, respectively. The Root Mean Square (RMS) of BSi and AuBSi is 20.8494 and 20.6259, respectively. These values that describe the height variations on the surface indicate that the surfaces are very similar to each other and they are flatter than micron-scaled objects, such as tissues 


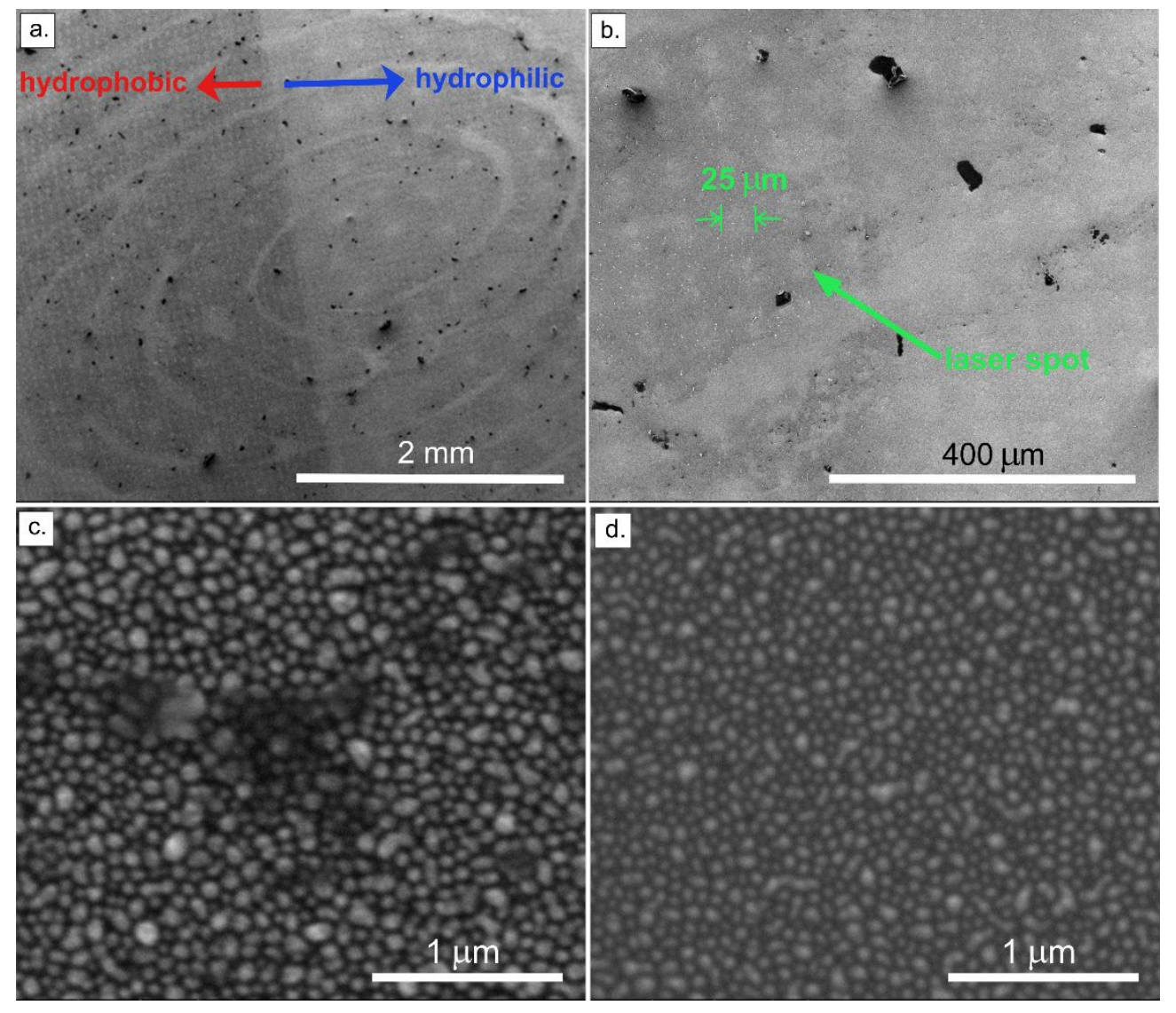

Figure S3. SEM images of the AuBSi nanostructure after fingerprint stamping and MSI acquisition $(\mathbf{a}, \mathbf{b}, \mathbf{c})$ and SEM image of a clean AuBSi $(\mathbf{d})$. Image a. shows the morphology of the fingerprint (ridges and valleys), with some parts that are darker than others because of the presence of carbon from the biomolecules adhered to the surface; image $\mathbf{b}$ shows the laser spots with average diameter around $25 \mu \mathrm{m}$ (in light grey color), small circular-like areas where the molecules desorbed from the AuBSi; image $\mathbf{c}$ is a close up inside one of the laser spots from image $\mathbf{b}$., where the darker grey indicates the presence of carbon and the lighter grey shows the presence of metal, in this case gold. The nanostructures in image $\mathbf{c}$ (after fingerprint imprinting and MSI analysis) and image d. (clean AuBSi surface) are very similar, indicating that the AuBSi structure is robust enough to stamp samples onto the surface 


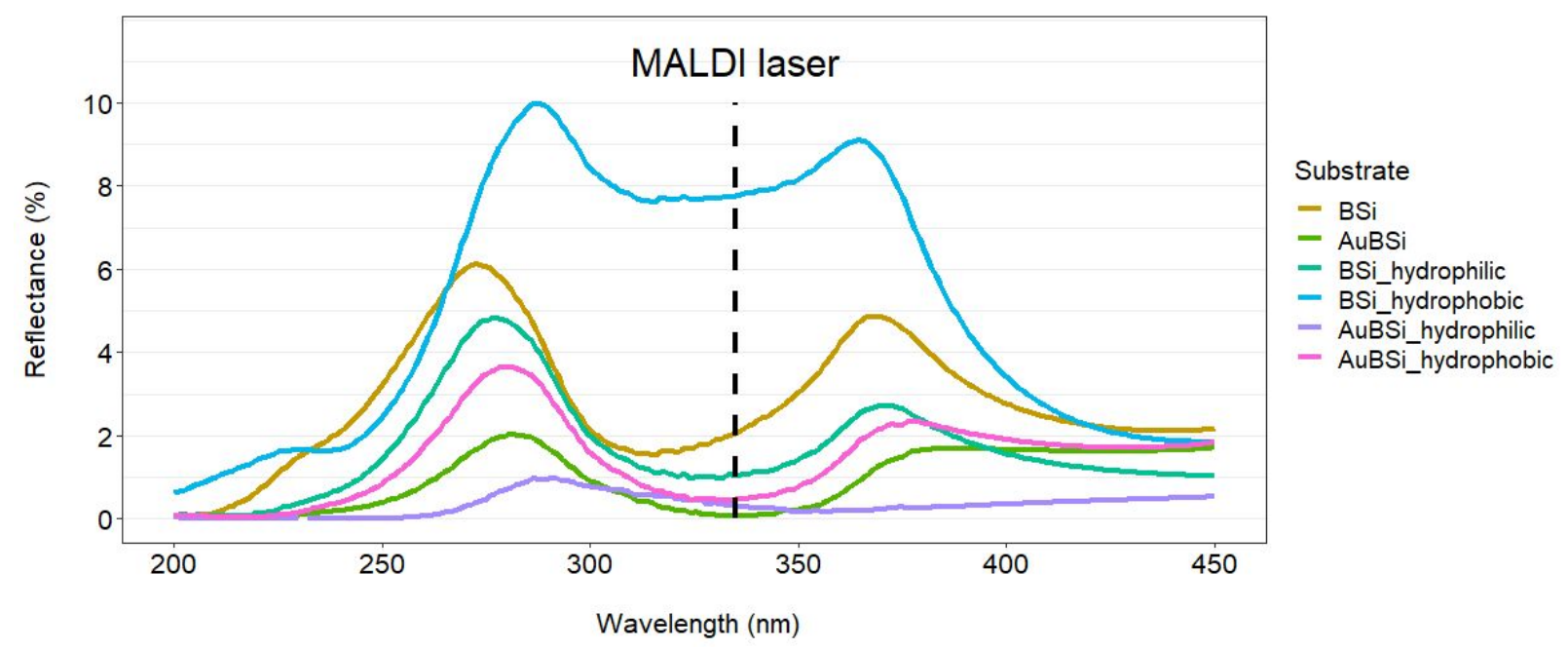

Figure S4. Reflectance of bare Si, BSi and AuBSi substrates and their modified surfaces. The dashed line marks the MALDI UV laser wavelength at $335 \mathrm{~nm}$. The value of reflectance for bare silicon for the range $200-450 \mathrm{~nm}$ is higher than $50 \%$
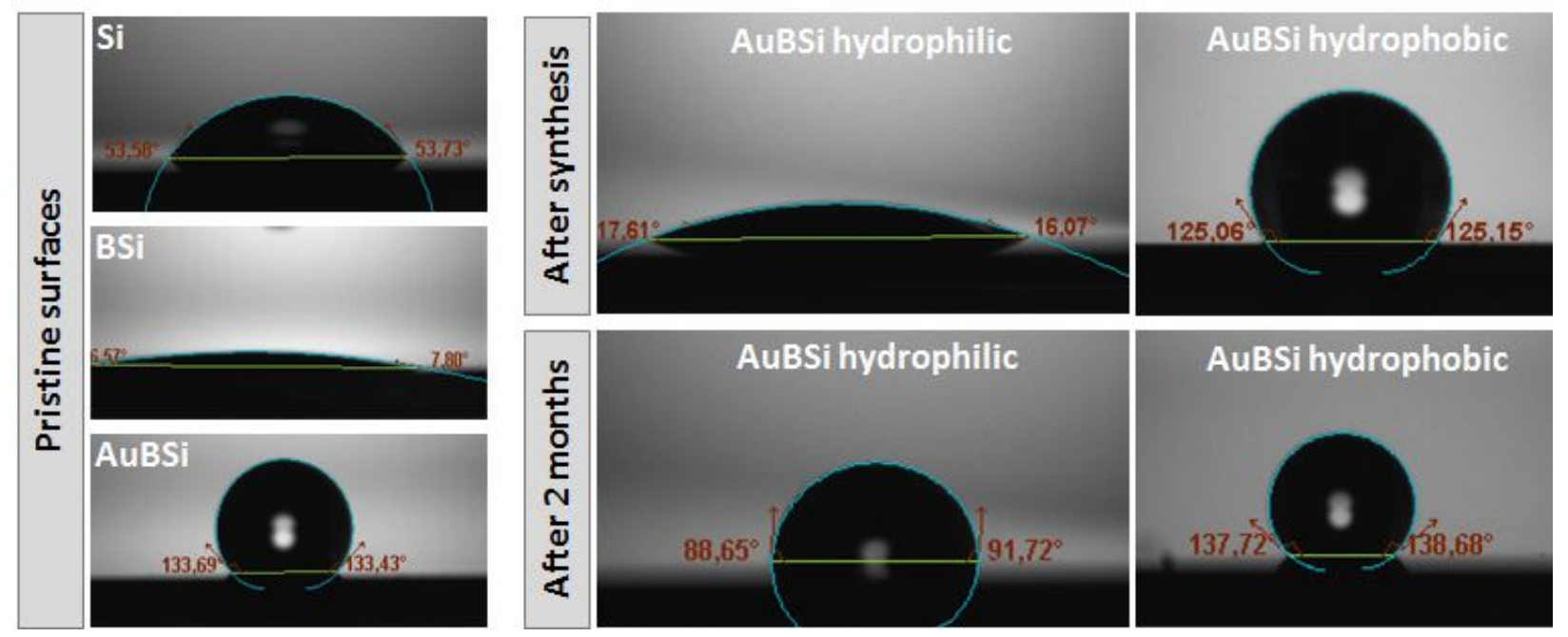

Figure S5. Contact angle measurements of bare $\mathrm{Si}, \mathrm{BSi}, \mathrm{AuBSi}$ and functionalized AuBSi surfaces after synthesis and 2 months after synthesis 


\section{Fabrication protocol of BSi and AuBSi array of wells}

For the analysis of liquid samples we created an array of black silicon (BSi) and gold-coated black silicon (AuBSi) wells on which the liquid standards would be spotted. For this, we used a custom made inox mask to cover the Si wafer while creating the BSi. First we placed the wafer into the RIE chamber, then we placed the inox mask on the wafer and used a mixture of oxygen $\left(\mathrm{O}_{2}\right)$ and sulfur hexafluoride $\left(\mathrm{SF}_{6}\right)$ gasses of ratio 1:1 (30 mTorr, $\left.200 \mathrm{~W}, 10 \mathrm{~min}\right)$ to create the BSi wells, only where the wafer was exposed (in the holes of the mask). Then we removed the mask and placed the wafer into the Sputtering chamber and deposited $10 \mathrm{~nm}$ Au layer (Ar atmosphere 30 mTorr, $35 \mathrm{~mm}$ working distance, RF mode at $100 \mathrm{~W}$ for $72 \mathrm{~s}$ ) to obtain AuBSi wells. The Au layer deposited on the Si wafer created a hydrophobic surface, therefore we changed the hydrophobicity of the wells for optimizing the sample deposition. For this, we placed the gold-coated wafer into the RIE chamber and put the inox mask onto the wafer so the wells aligned with the holes of the mask. We then used oxygen plasma $(50 \mathrm{sccm}, 150 \mathrm{~W}, 50 \mathrm{mTorr}, 75 \mathrm{~min})$ to create hydrophilic AuBSi wells. Figure S6 represents the fabrication steps for the BSi and AuBSi well array. 


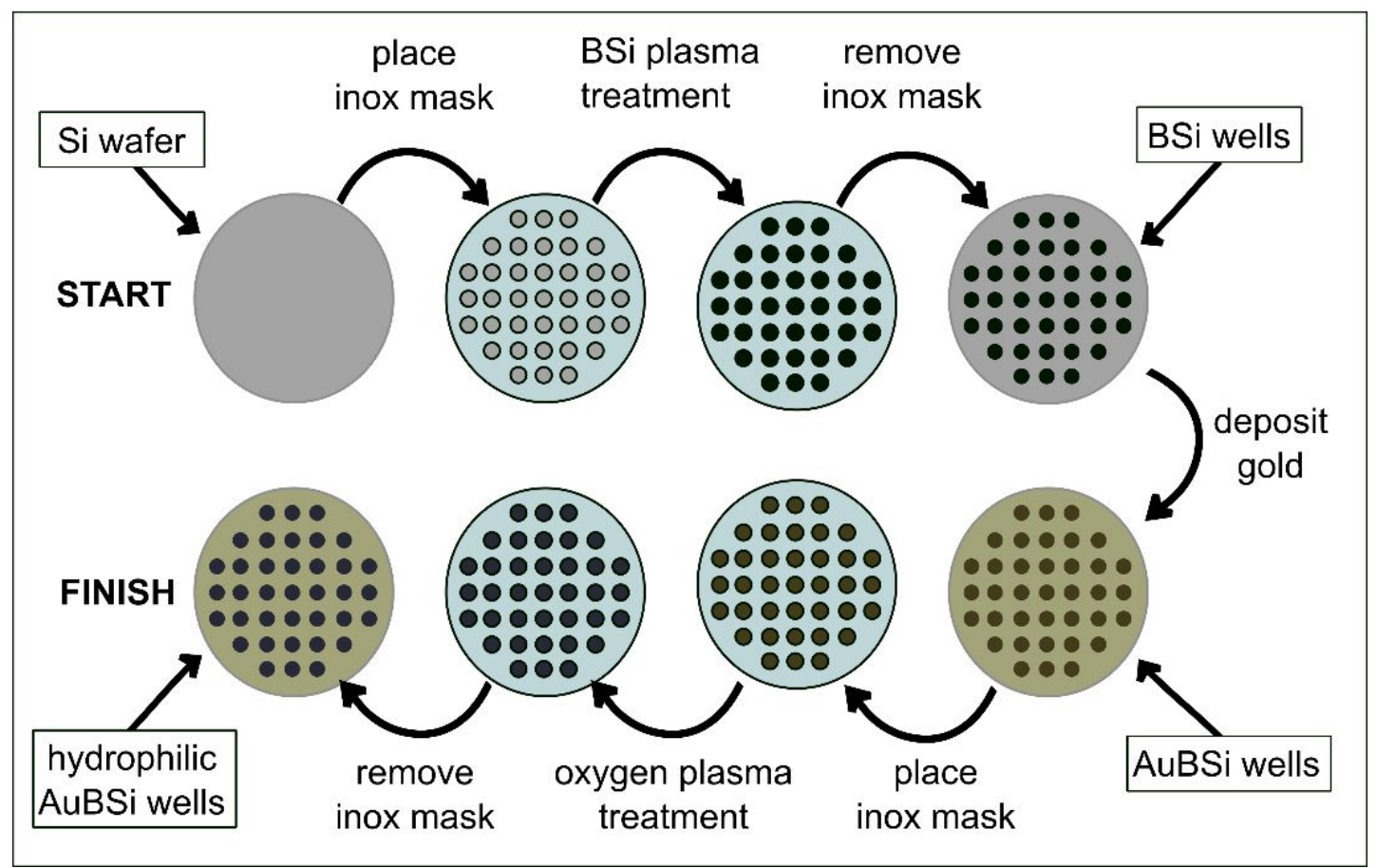

Figure S6. Fabrication steps for the array of hydrophilic AuBSi wells. 


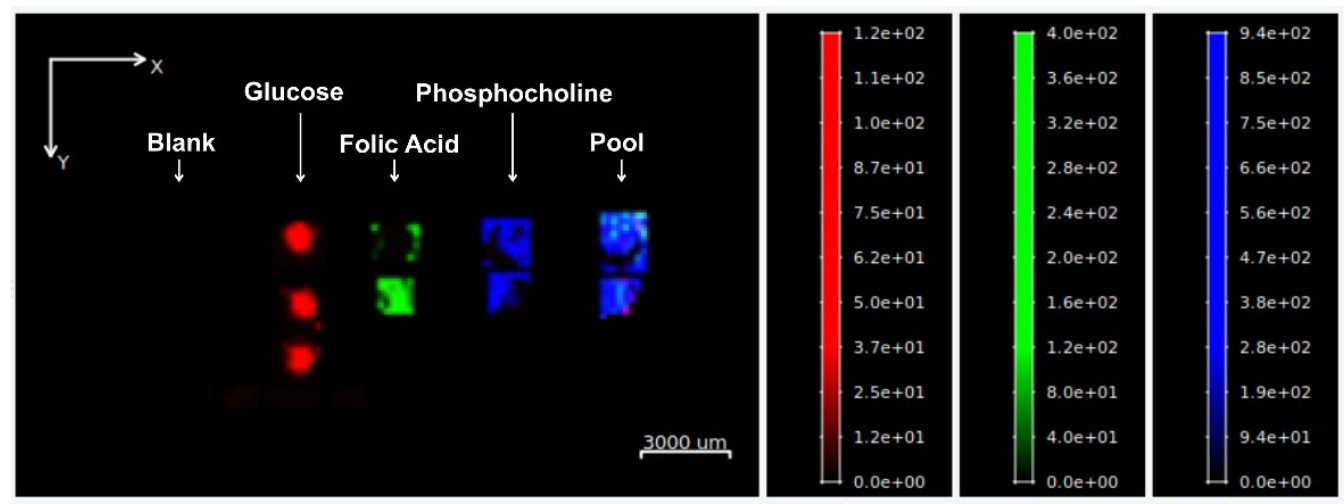

A. All standard solution droplets on BSi wells

ON 203.09 Da ON 295.12 Da ON 184.11 Da

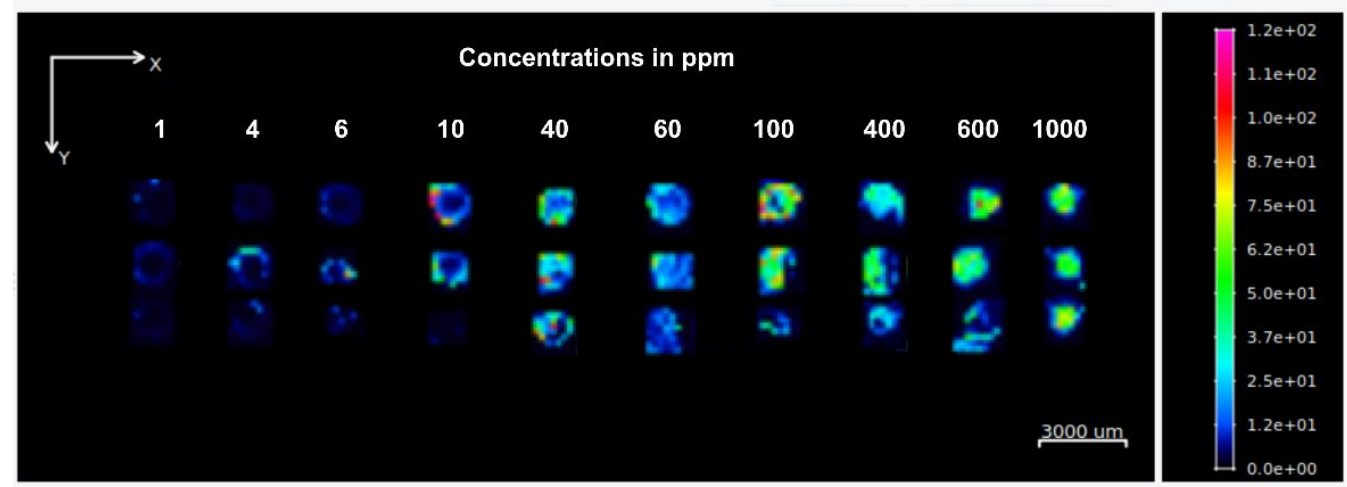

B. Glucose standard solution droplets on BSi wells

ON 203.09 Da
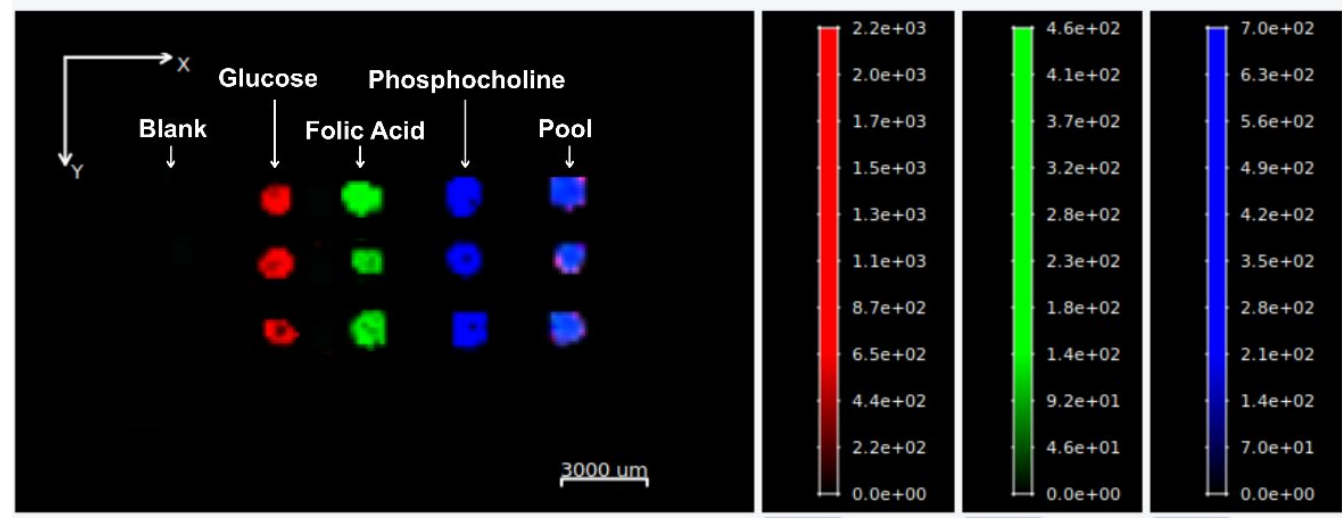

C. All standard solution droplets on AuBSi wells

ON 203.05 Da ON

ON $184.07 \mathrm{Da}$
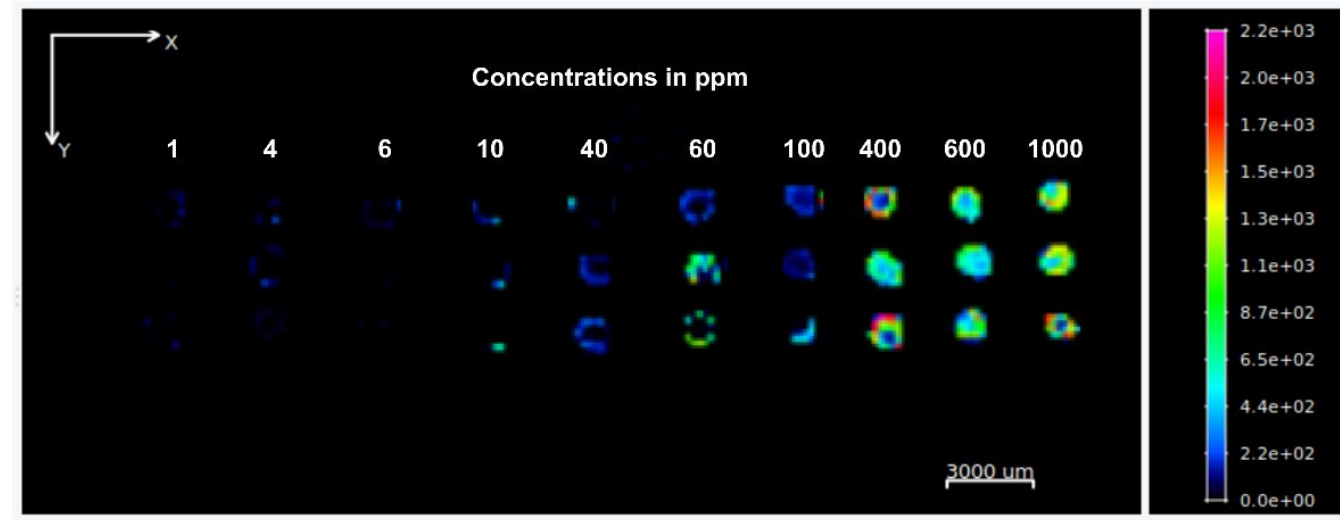

D. Glucose standard solution droplets on AuBSi wells

ON 203.05 Da 
Figure S7. MS images of standard droplets on BSi and AuBSi normalized by TIC. (A, C) Visualization of the three standards (1000 ppm in water/methanol 1:1, v/v), the pool and the blank using 3 color channels: red for glucose $\mathrm{m} / \mathrm{z} 203.05$, green for folic acid $\mathrm{m} / \mathrm{z} 295.1$ and blue for phosphocholine $\mathrm{m} / \mathrm{z}$ 184.07. (B, D) Visualization of the 10 concentrations of glucose (1-1000 ppm in water/methanol 1:1, v/v).

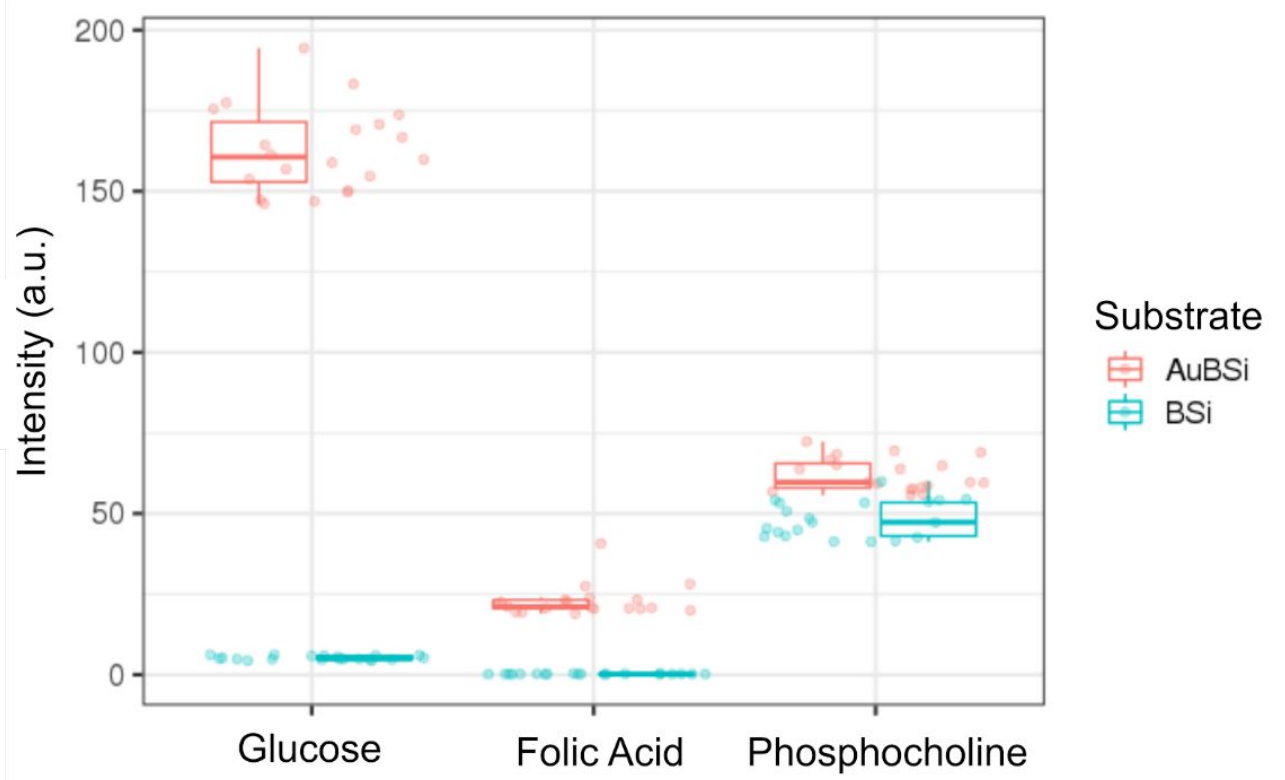

Figure S8. Boxplot chart comparing the intensity values of the representative ions of the three standards measured on BSi and AuBSi substrates (glucose $\mathrm{m} / \mathrm{z} 203.05$; folic acid $\mathrm{m} / \mathrm{z} 2$ 295.1; phosphocholine $m / z$ 184.07). Each boxplot contains the 20 most intense pixels from the 3 droplets measured (see in Figure S7). 

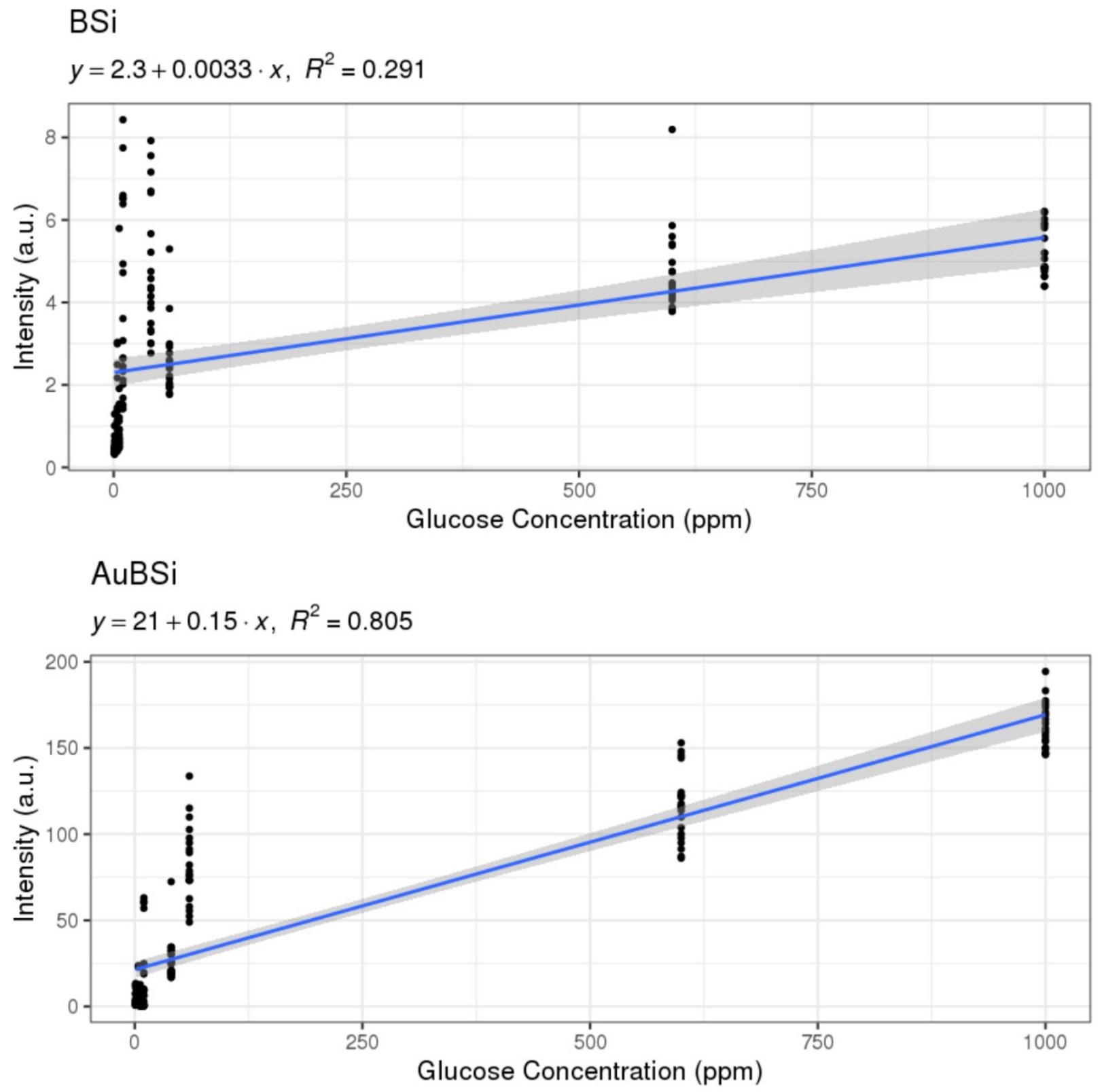

Figure S9. Linear calibration curves of glucose in the range of 1-1000 ppm measured on BSi and AuBSi. For each glucose concentration the 20 most intense pixels are used for calculations. 

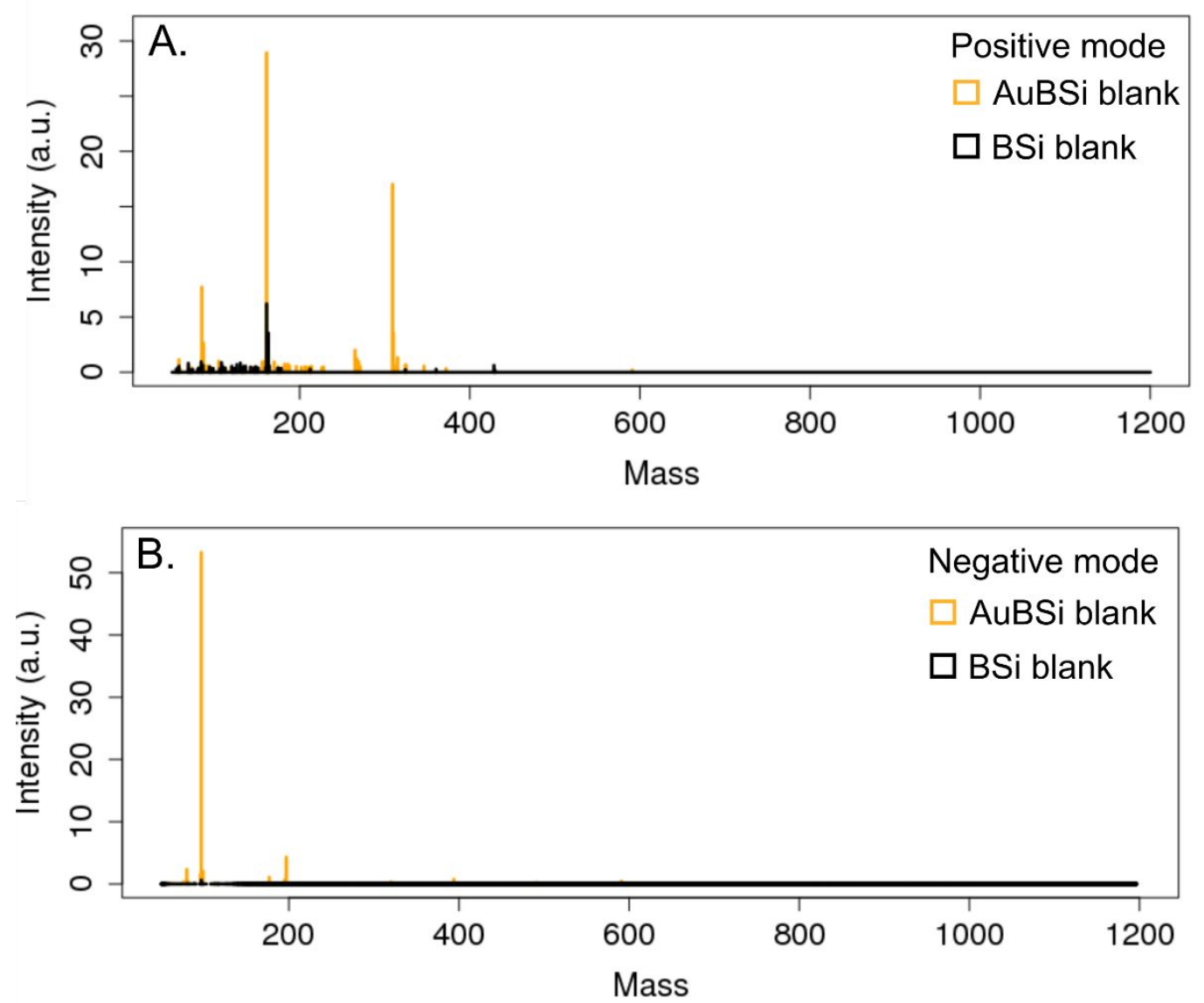

Figure S10. Background (blank) mass spectra from BSi and AuBSi in positive (A.) and negative mode (B.). Peaks detected in these background samples are situated in the low mass region of the spectra $(m / z 50-300)$ with low intensity compared to intensity from fingermarks, Figure 3 in the main manuscript. 


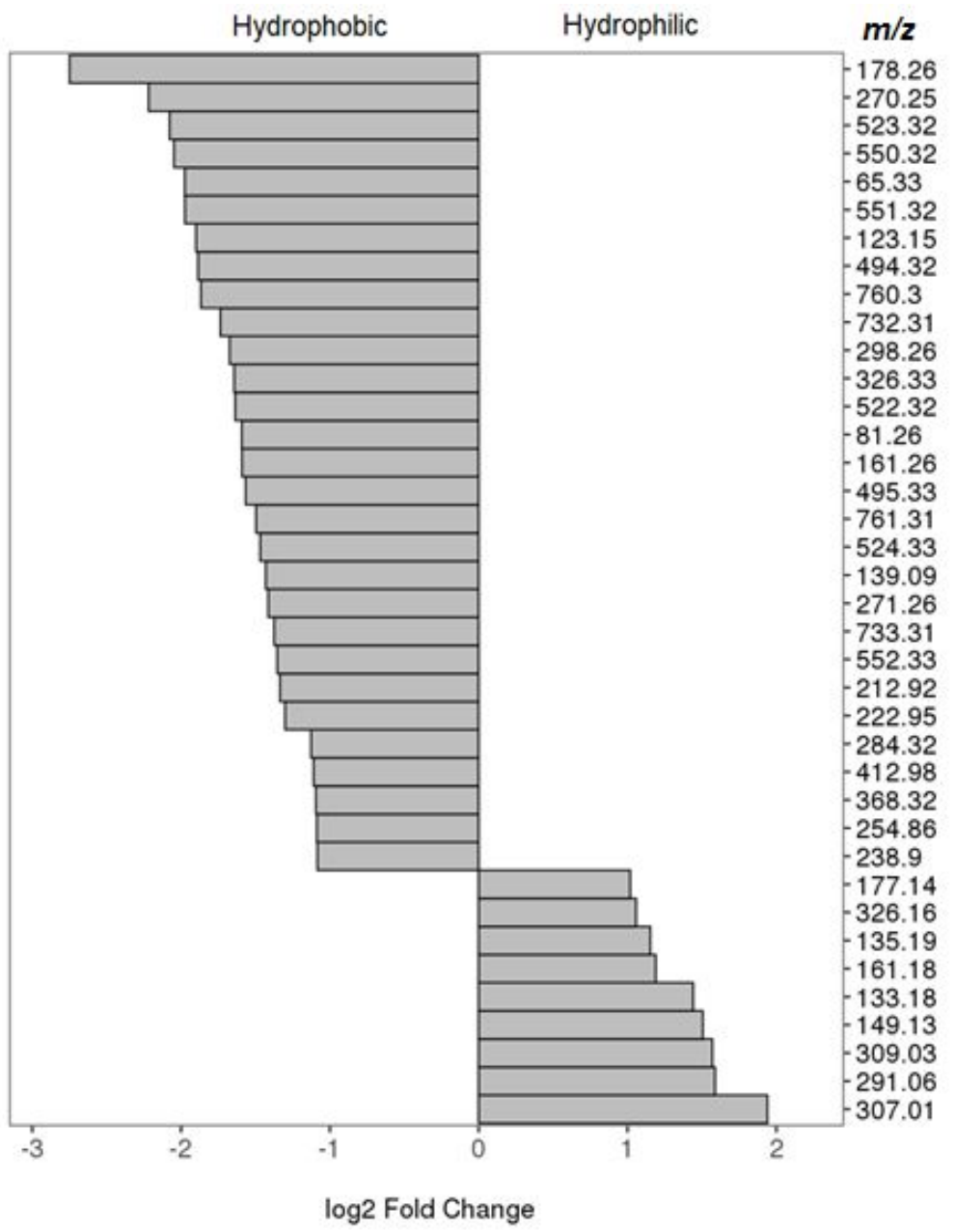

Figure S11. Fold change plot showing the predominant ions $(\mathrm{m} / \mathrm{z})$ in the hydrophobic and hydrophilic regions 


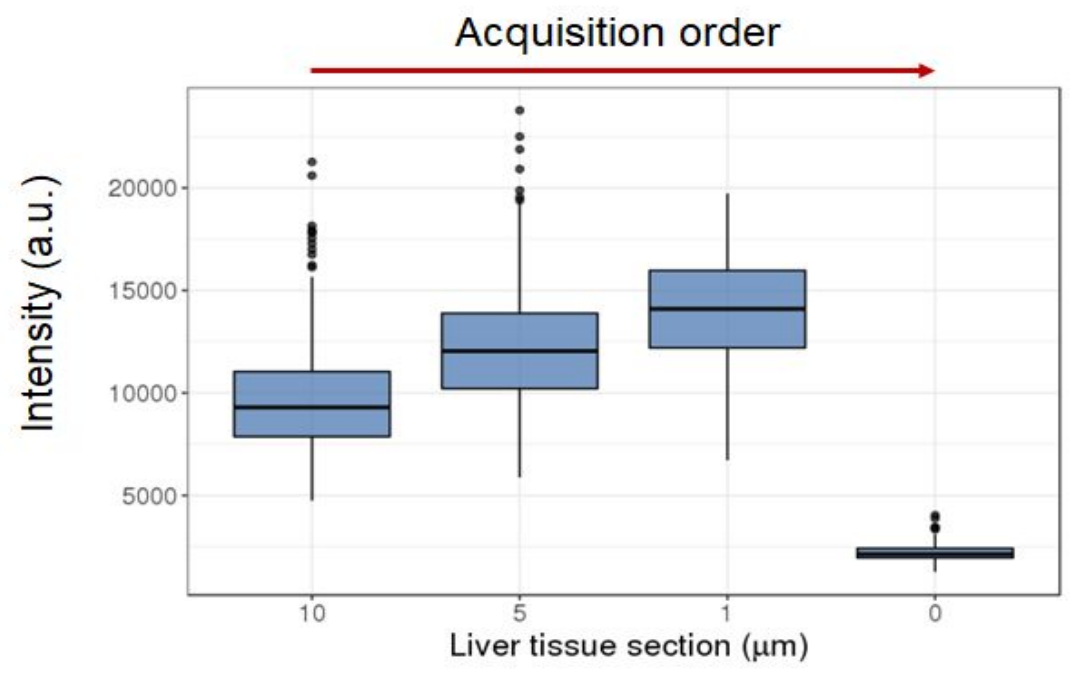

Figure S12. Boxplot representation of total ion count for the different liver sections used for the molecule transfer method in acquisition order 
Table S1. Putative identification of brain and kidney ions detected on AuBSi

\begin{tabular}{|c|c|c|c|c|c|c|c|}
\hline Compound Name & $\begin{array}{l}\text { Chemical } \\
\text { Formula }\end{array}$ & Adduct & $\begin{array}{c}\text { Theoretica } \\
1 \mathrm{~m} / \mathrm{z}\end{array}$ & $\begin{array}{c}\text { Experiment } \\
\text { al } m / z\end{array}$ & $\begin{array}{l}\text { Error } \\
\text { [ppm] }\end{array}$ & Sample & Ref \\
\hline (3'-sulfo)Gal $\beta$-Cer(d18:1/18:0) & $\begin{array}{c}\mathrm{C} 42 \mathrm{H} 81 \mathrm{NO} 11 \\
\mathrm{~S}\end{array}$ & {$[\mathrm{M}-\mathrm{H}]-$} & 806.5458 & 806.5535 & 9.546 & brain & 1,2 \\
\hline PG(40:6) & $\mathrm{C} 46 \mathrm{H} 79 \mathrm{O} 10 \mathrm{P}$ & {$[\mathrm{M}-\mathrm{H}]-$} & 821.5338 & 821.5591 & $\begin{array}{c}30.79 \\
6\end{array}$ & brain & $1-3$ \\
\hline $\begin{array}{l}\left(3^{\prime} \text {-sulfo)Gal } \beta \text { - }\right. \\
\text { Cer(d18:1/18:0(2OH)) }\end{array}$ & $\begin{array}{c}\mathrm{C} 42 \mathrm{H} 81 \mathrm{NO} 12 \\
\mathrm{~S}\end{array}$ & {$[\mathrm{M}-\mathrm{H}]-$} & 822.5407 & 822.5328 & 9.604 & brain & 2,3 \\
\hline (3'-sulfo)Gal $\beta$-Cer(d18:1/22:0) & $\begin{array}{c}\mathrm{C} 46 \mathrm{H} 89 \mathrm{NO} 11 \\
\mathrm{~S}\end{array}$ & {$[\mathrm{M}-\mathrm{H}]-$} & 862.6084 & 862.6261 & $\begin{array}{c}20.51 \\
9\end{array}$ & brain & $1-3$ \\
\hline $\begin{array}{l}\text { (3'-sulfo)Gal } \beta \text { - } \\
\text { Cer(d18:1/22:0(2OH)) }\end{array}$ & $\begin{array}{c}\mathrm{C} 46 \mathrm{H} 89 \mathrm{NO} 12 \\
\mathrm{~S}\end{array}$ & {$[\mathrm{M}-\mathrm{H}]-$} & 878.6033 & 878.6169 & $\begin{array}{c}15.47 \\
9\end{array}$ & brain & 2,3 \\
\hline (3'-sulfo)Galß-Cer(d18:1/24:1(15Z)) & $\begin{array}{c}\text { C48H91NO11 } \\
\text { S }\end{array}$ & {$[\mathrm{M}-\mathrm{H}]-$} & 888.624 & 888.591 & $\begin{array}{c}37.13 \\
6\end{array}$ & brain & $1-3$ \\
\hline (3'-sulfo)Gal $\beta$-Cer(d18:1/24:0) & $\begin{array}{c}\text { C48H93NO11 } \\
\mathrm{S}\end{array}$ & {$[\mathrm{M}-\mathrm{H}]-$} & 890.6397 & 890.6341 & 6.287 & brain & $1-3$ \\
\hline $\begin{array}{l}(3 ' \text {-sulfo)Gal } \beta \text { - } \\
\operatorname{Cer}(\mathrm{d} 18: 1 / 24: 1(15 \mathrm{Z})(2 \mathrm{OH}))\end{array}$ & $\begin{array}{c}\text { C48H91NO12 } \\
\text { S }\end{array}$ & {$[\mathrm{M}-\mathrm{H}]-$} & 904.6189 & 904.5851 & $\begin{array}{c}37.36 \\
3\end{array}$ & brain & 2,3 \\
\hline $\begin{array}{l}(3 \text { '-sulfo)Gal } \beta \text { - } \\
\text { Cer(d18:1/24:0(2OH)) }\end{array}$ & $\begin{array}{c}\mathrm{C} 48 \mathrm{H} 93 \mathrm{NO} 12 \\
\mathrm{~S}\end{array}$ & {$[\mathrm{M}-\mathrm{H}]-$} & 906.6346 & 906.6489 & $\begin{array}{c}15.77 \\
2\end{array}$ & brain & 2,3 \\
\hline stearic acid & $\mathrm{C} 18 \mathrm{H} 36 \mathrm{O} 2$ & {$[\mathrm{M}-\mathrm{H}]-$} & 283.2643 & 283.27911 & $\begin{array}{c}52.28 \\
3\end{array}$ & kidney & $1,2,4$ \\
\hline PE(P-18:0/22:4(7Z,10Z,13Z,16Z)) & C45H82NO7P & {$[\mathrm{M}-\mathrm{H}]-$} & 778.5756 & 778.5687 & 8.862 & kidney & 2,3 \\
\hline PE(MonoMe(11,3)/MonoMe(13,5)) & $\begin{array}{c}\mathrm{C} 47 \mathrm{H} 82 \mathrm{NO} 10 \\
\mathrm{P}\end{array}$ & {$[\mathrm{M}-\mathrm{H}]-$} & 850.5604 & 850.5736 & $\begin{array}{c}15.51 \\
9\end{array}$ & kidney & 1 \\
\hline $\operatorname{PE}(22: 4(7 Z, 10 Z, 13 Z, 16 Z) / 24: 0)$ & C51H94NO8P & {$[\mathrm{M}-\mathrm{H}]-$} & 878.6644 & 878.6532 & $\begin{array}{c}12.74 \\
6\end{array}$ & kidney & 1 \\
\hline PE-NMe2(46:4) & C53H98NO8P & {$[\mathrm{M}-\mathrm{H}]-$} & 906.6957 & 906.68 & $\begin{array}{c}17.31 \\
5\end{array}$ & kidney & 1 \\
\hline
\end{tabular}




\section{References}

(1) Wishart, D. S.; Feunang, Y. D.; Marcu, A.; Guo, A. C.; Liang, K.; Vázquez-Fresno, R.; Sajed, T.; Johnson, D.; Li, C.; Karu, N.; Sayeeda, Z.; Lo, E.; Assempour, N.; Berjanskii, M.; Singhal, S.; Arndt, D.; Liang, Y.; Badran, H.; Grant, J.; Serra-Cayuela, A.; et al. HMDB 4.0: The Human Metabolome Database for 2018. Nucleic Acids Res. 2018, 46.

(2) Sud, M.; Fahy, E.; Cotter, D.; Brown, A.; Dennis, E. A.; Glass, C. K.; Merrill, A. H.; Murphy, R. C.; Raetz, C. R. H.; Russell, D. W.; Subramaniam, S. LMSD: LIPID MAPS Structure Database. Nucleic Acids Res. 2007, 35, 527-532.

(3) Cerruti, C. D.; Benabdellah, F.; Laprévote, O.; Touboul, D.; Brunelle, A. MALDI Imaging and Structural Analysis of Rat Brain Lipid Negative Ions with 9-Aminoacridine Matrix. Anal. Chem. 2012, 84, 2164-2171.

(4) Liu, H.; Li, W.; He, Q.; Xue, J.; Wang, J.; Xiong, C.; Pu, X.; Nie, Z. Mass Spectrometry Imaging of Kidney Tissue Sections of Rat Subjected to Unilateral Ureteral Obstruction. Sci. Rep. 2017, 7, 1-9. 